\title{
UMA CIÊNCIA DAS PRÁTICAS E SABERES ESPACIAIS
}

\author{
Geography: a practical and to know science
}

\section{Una ciência de las prácticas e saberes espaciales}

\author{
Ruy Moreira \\ ruymoreira@uol.com.br
}

Artigo recebido em 18/09/2017 e aceito para publicação em 19/10/2017

DOI: $10.12957 /$ tamoios.2017.30458

\section{Resumo}

As relações geográficas são relações de prática e saber espacial dialeticamente combinadas como uma práxis. Da economia às manifestações culturais, as atividades humanas são uma sequência de práticas e saberes espaciais, porque a vida humana em resumo é um conjunto de unidades de práxis de cunho espacial. Há diversas formas de práticas segundo se viva na cidade e no campo. E é este o tema do estudo geográfico.

Palavras-chave: relações geográficas; espaço; prática espacial; saber espacial; modo espacial de vida

\begin{abstract}
Geographical relations are spacial practic and to know relations dialectily combined as a praxis. From economic productions to cultural manifestations human activities are a sequency of spacial practics. The human life is this geographical relationship conjunctions because our way of life in city and country depends of the several kinds of spacial practical activities we live. And this is the theme of geographical studies.
\end{abstract}

Key words: geographical relations; space; spacial pratic; to know spacial; way spacial of life

\section{Resumen}

Las relaciones geográficas son relaciones de prácticas y saberes espaciales dialecticamente combinadas como una praxis. De la economia a las formas de manifestaciones culturales las actividades humanas son una sucessión de formas de prácticas y saberes espaciales porque la vida humana es en resumen la combinación dessas relaciones geográficas. Hay diferentes formas de prácticas y saberes segun se viva en la ciudad y en el campo que constituyen nuestro modo espacial de vida. Y que componen el objeto de los estudios de la Geografia.

Palabras claves: Relaciones geográficas; espacio; práctica espacial; saber espacial; modo de vida. 
A construção geográfica de uma sociedade é um processo de práticas e saberes espaciais dialeticamente interligados numa práxis. Os saberes espaciais que vêm das práticas. E as práticas espaciais que por meio daqueles se orientam. A sociedade geograficamente edificada é o fruto desse amálgama. Como também a própria Geografia.

São as práticas e os saberes espaciais em sua reciprocidade interativa que comandam as relações de determinação entre a sociedade e o espaço em cada contexto de história. E é essa mesma relação saber-prática que se expressa naquela outra do saber do senso comum, o saber do cotidiano dos homens e mulheres, e do saber científico, o saber elaborado dos acadêmicos.

O que chamamos espaço geográfico é o todo desse amálgama em que geografia é a objetividade do real vivido e Geografia a subjetividade do vivido como real pensado, seja como senso comum e seja como abstratividade científica. Geograficididade e reflexividade. Tudo brotado da mesma relação de práxis do saber e da prática.

\section{PRÁtica E SABER. SENSO COMUM E CiênCIA. GEOGRAFIA E GEOGRAFIA. BURILANDO O JOGO DOS CONCEITOS}

Tudo na vida humana começa e se resolve nas práticas espaciais. Atividade que ocorre no âmbito da relação homem-natureza, no momento e colagem da busca do homem de prover-se de meios de vida em contato com as fontes naturais do meio circundante, a prática ambiental, e daí se desdobram para autonomizar-se em práticas sociais, políticas, culturais. Sob essas diferentes formas, a prática espacial é o instrumento de toda edificação. As necessidades da vida são o móvel das práticas espaciais. O mesmo que dizer das práticas espaciais como respostas moventes das necessidades da vida humana. Quando uma comunidade humana entra em contato com o solo agrícola, por exemplo, o móvel é a busca do homem de extrair desse solo o que este lhe oferece de possibilidade de existência. E o espaço organizado a resposta teórica e prática

O saber espacial vem dessa dinâmica prática da prática. A leitura abstrata do pensamento da vivência do empírico trazida da prática espacial. A sistematização pela qual o pensamento une na linguagem universal da fala o imediato dos detalhes isolados e singulares do mundo empírico transformado no mediato do concreto pensado. É assim que, continuando no exemplo do uso do solo, do curso experiencial da prática espacial a 
pouco e pouco vai brotando a noção do melhor modo de realizar este cultivo ou aquela criação, o melhor ponto local para fazê-lo, a ou as espécies mais apropriadas para uma consorciação de policultura, a combinação de lavoura e criação mais adequada a uma rotação de terras ou de culturas, o melhor modo de extrair o melhor resultado possível da ação, transformando os detalhes e singularidades isolados da empiria na unidade totalizada do concreto-pensado.

Orientada, então, no saber, a prática espacial avança. E o seu avanço empurra a marcha de captação ideal para um plano ainda maior daquela. Saber e prática desdobrando a noção ainda prenhe de empiria do senso comum na ideação já plena de abstrato do conceito. Também aqui a práxis é a mãe do desenvolvimento. A prática orientada é estimulada a deslocar-se do ponto-começo sucessivamente para novas áreas, levando a ideação do saber a ampliar-se em generalização na escala comparativa de um número sempre maior de experiências práticas, pela qual as categorias nocionais do saber do senso corrente ganham o caráter universal das categorias conceituais do saber sistemático da ciência. Passo que alça a práxis saber-prática do senso comum do vivido à práxis saber-prático do discurso abstrato da Geografia.

E é esse duplo do nível empírico-cotidiano do senso comum, o plano do âmbito prática-saber do mundo vivido, e do nível abstrato-concreto da universalidade científica, o plano do âmbito prática-saber do discurso formal-científico, o duplo do real que vai diferir a geografia da Geografia. A geografia empírico-existencial do espaço vivido e a Geografia concreto-abstrata do discurso científico. O duplo do significado que distingue a geografia como o real-empírico (a geograficidade) e a Geografia como o real-pensado (a reflexão sobre o ser-estar espacial do homem), introjetados, sob o mesmo termo, pela fonte seminal das práticas e saberes espaciais.

\section{AS FASES E FORMAS DA PRÁTICA ESPACIAL}

Toda sociedade é geograficamente o acúmulo da sucessão de práticas espaciais que a constróem e nesse passo vão se desdobrando e se sobrepondo uma nas outras, numa edificação de estrutura complexa e cíclica, das quais a seletividade é a primeira. 


\section{A seletividade}

A prática espacial começa, e recomeça, na seletividade. A seletividade é o processo de eleição do local com que a sociedade inicia a montagem da sua construção geográfica. Espécie de ponte entre a história natural e a história social se expressando já em termos de espaço, a seletividade é uma decorrência direta do princípio da localização geográfica, uma vez que é por meio da escolha da localização que o homem elege a melhor possibilidade de fixação e organiza as relações espaciais com que vai erguer seu habitat.

A seletividade se orienta por um processo de ensaio e erro, no decurso do qual sucessivamente a sociedade se ambientaliza, se territorializa e se enraiza culturalmente (Moreira, 2006), experimentando diferentes locais, que Vidal La Blache designa "áreas laboratórios", antes de sedentarizar-se (Vidal La Blache, 1954). Dando início à história da civilização humana, as "áreas laboratórios" são escolhidas entre os locais localizados nas encostas montanhosas, mais secas e menos abundantes em recursos, porém mais abrigadas da ameaça de animais de maior porte. Aí praticada, por um longo período, a seletividade limita-se a se confundir com o processo da aprendizagem da domesticação e da aclimatação da flora e da fauna local, no curso da qual o grupo humano migra entre uma área microclimática e outra de mesmo quadro mesoclimatico, num acúmulo de forças e experiência, até que, a seguir, já munido do domínio do trato ambiental, desce para as "regiões anfíbias", os lugares de "mesa posta" dos vales dos grandes rios, nos quais se fixa em caráter permanente, dando origem ao surgimento das grandes civilizações.

A seletividade é a origem do que Brunhes chama os cheios e vazios do espaço, isto é, o todo das casas, caminhos e manchas de atividades econômicas, que compõem a forma e o conteúdo dos arranjos do habitat cuja configuração varia de acordo com o tempo e o lugar históricos (Brunhes, 1962). É a seletividade que responde pelo elenco das espécies de plantas e animais com que a sociedade se relaciona com o meio. Amplo no começo, este elenco vai se qualificando no tempo, até que com a sedentarização vai limitar-se a um pequeno número. Calculadas no conjunto em 140 ou 150 mil, somente cerca de 300 espécies vegetais e 200 espécies do reino animal são ao fim aproveitadas. O restante sendo preservado e estabelecidos como âmbito geral de envolvimento da criação e cultivos aí desenvolvidos. A causa dessa relação uso-preservação é a lógica histórica que a preside. Nas fases primitivas da coleta, caça e pesca a humanidade se 
$\overline{\text { relaciona com toda a diversidade de flora e fauna do meio. O nascimento da agricultura }}$ leva ao surgimento da técnica. E esta à transformação das paisagens naturais em paisagens humanizadas. A técnica aumenta a produção e a troca, técnica e intercâmbio econômico tornando-se a base da constituição dos modos de vida e da eleição seletiva das espécies entre consumidas e não usadas que então se estabelece. A progressão é a ação redutora que surge do avanço da relação de troca, restringindo as associações naturais às associações domesticadas. $\mathrm{O}$ fio condutor é a conversão da paisagem natural num complexo alimentar, que Sorre define como o conjunto dos alimentos e preparos nutritivos graças aos quais um grupo humano mantém sua existência ao longo de um ano. E o complexo alimentar num complexo mercantil, que Sorre define como o conjunto dos elementos da fauna e flora selecionados para o fim mais sofisticado de elenco regulador das trocas tornadas permanentes entre as comunidades (Sorre, 1967). Originalidade natural e parcialidade seletiva coexistem, porém, ainda, o todo da fauna e flora mantendo-se fundamentalmente ainda o mesmo de antes. A chegada da sociedade moderna leva a seleção a ganhar, todavia, o sentido restritivo de lucro que hoje conhecemos. Governada pela lógica do mercado, a seletividade é agora transformada numa prática cada vez mais especializada e fragmentária do uso e arranjo do espaço, a construção geográfica da sociedade se orientando pela e em função de uma divisão territorial do trabalho que baixe os custos e aumente a produtividade, no propósito acumulativo capitalista. No interesse da troca, como observam Quaini e Smith, em que os valores-de-uso são avaliados e filtrados pelo parâmetro do valor-de-troca, a seletividade se converte num mecanismo de descarte de espécies, limitador do número de espécies aceitas, de modo que ecossistemas inteiros são reduzidos a filetes de resíduos do que eram antes, quando não se elimina de todo (Quaini, 1979 e Smith, 1988). A espacialidade humana assim se desambientaliza, se desterritorializa e se desenraiza inteiramente, numa desespacialidade em que o homem perde por fim sua identidade com o meio (Moreira, 2007c).

\section{A unodiversidade}

A seletividade desdobra-se na unomultidiversidade. Por conta da naturalidade o espaço nasce diverso. A diversidade multiplica e transforma a localização seletiva numa distribuição locacionalmente múltipla de lugares e faz do todo do arranjo um habitat humano plural. Esse todo sistêmico de distribuição múltipla de localizações 
seletivamente escolhidas converte-se numa configuração de extensão progressivamente ampla de possibilidades de vida socialmente criadas. As diferenças hídrica, topográfica, do solo, da flora, da fauna, das casas, dos caminhos, das culturas orientam o habitat para a diversidade, a diversidade dos múltiplos gêneros e modos de vida distintamente ambientalizados em suas micro e meso áreas, que Vidal diz expandir-se umas em relação às outras "à maneira das abelhas", não de uma mancha de óleo, cujo efeito é múltiplo das diferenças que distingue as civilizações do passado.

São modos de vida que resultam do casamento dos diferentes homens com diferentes ecossistemas, fruto de gêneros de vida territorializados em ambientes costeiros, montanhosos, florestais e de savanas, a exemplo da pesca, da coleta e da caça, multiplicados aqui e ali ilimitadamente. Com a descoberta do fogo e o surgimento da agricultura, as comunidades humanas ainda mais se dispersam, se multiplicam e se adensam. E o leque da diversidade das formas de ocupação do espaço aumenta. A diversidade da natureza multiplica-se assim na diversidade da criação cultural do homem, multiplicando-se as formas de gêneros de vida de vida simples ao tempo que as formas de gêneros de vida complexos. Diversidade que no começo dos tempos modernos se mantém aos trancos e barrancos, até que fenece, face à invasão da uniformidade da técnica e da lógica do mercado que a tudo pradroniza, uniciza e reordena na mesma unidade uniformizada de espaço, globalizando e ameaçando a diversidade de cultura dos grupos humanos e suas múltiplas formas de ocupação.

\section{A unicidade}

Por isso o espaço também nasce uno. A unidade que é, tanto quanto a diversidade, intrínseca seja à natureza e seja às práticas da seletividade. A unidade que está implícita já no trabalho que faz dos homens uma comunidade. E na relação coletiva que estes levam para sua relação de seletivadade com o meio que ocupam. Assim, para cada diversidade de espaço humano espalhado pela superfície terrestre, uma unidade de coabitação que une os homens numa mesma comunidade aparece em correspondência. Unidade que vem seja do valor simbólico seja do valor econômico que norteiam a costura das relações. A unidade do símbolo cultural dos gêneros de vida e a unidade metabólica do trabalho. Uma e outra retransfigurada na forma própria de unidade estrutural e orgânica do espaço de cada comunidade. 
A unidade simbólica pode vir da relação ambiental, como na relação com a água: onde esta é o recurso central e fator de aglutinação, a unidade dos homens tem por base as regras do seu uso; na relação com a flora: vezes há em que a fonte do elemento simbólico é a vegetação, como no exemplo da formação espacial européia florestal temperado-fria do norte ou promíscua dos garriques e maquis secos e espalhados do sul; na relação com o todo: vezes há que esse papel cabe entretanto ao sítio, como numa região de lagos suíços, ou ao sistema de acesso hídrico, como numa região de regulação hidráulica mediterrânica. Bem como pode vir da relação direta das construções humanas, como na relação perceptiva do espaço vivido; na relação do poder político que vemos surgindo no Renascimento, quando o Estado unifica a nação, dá-lhe o símbolo de unidade e por meio deste constitui o Estado Nacional; na relação de mando territorial da cidade, como na Antiguidade, quando, ao contrário, é a cidade que difunde o poder do Estado, emprestando, inversamente, sua imagem como o símbolo de referência da unidade política deste. Mas a unidade do espaço é função também do valor, o valor mediador da moeda e o valor transformador da técnica. Ou das duas combinadas. Desde a Antiguidade, mas sobretudo na Idade Moderna, a moeda é a fita métrica que constitui a unidade medida do espaço. Ao agir, por exemplo, como um instrumento de construção do Estado na história, é a moeda que simbolicamente unifica o território. É a moeda o ente que encarna a partir do Renascimento a caracterologia do Estado nacional e a ideologia do progresso econômico. Assim se consolidando como sinônimo de garantia do acesso ao consumo e à elevação do nível de vida (Moreira, 1999 e 2007a; e Harvey, 1992). A técnica por sua vez é o elo que atua como ação prática e como imaginário Fala-se de razão técnica, falando-se da construção da unidade do espaço, simbolizando no plano concreto da territorialidade do terreno o poder da força que unifica e globaliza como espaço concreto a escala nacional da modernidade (Vidal La Blache, 1954). Mas símbolo cultural e valor econômico geralmente caminham também juntos. Como através a combinação da moeda e da técnica com a realidade simbólica, a moeda aparecendo como o símbolo monetário do dinheiro e a técnica como o símbolo prático da razão instrumental, moeda e técnica objetivando a subordinação subjetiva aos desígnios objetivos da economia. A modernidade se costurou como ideologia e concreticidade justamente nessa cumplicidade do valor e da técnica com o símbolo do imaginário, tornando-a indissociável da suprestrutura simbólica e da infraestrutura material no modo do espaço vivido em que estamos. O mundo que não se distingue das 
nossas representações. A tal ponto que imaginário do valor vivivo e representação ideológica de mundo tornam-se um só (Baudrillard, 1991 e 1996; e Melo, 1988).

\section{A tecnificação}

A seletividade e a unodiversidade se desdobram na tecnificação. A técnica é o instrumento-mor da ação e interação seletiva. Pelo seu significado de dupla via. De um lado ela é o produto da ambientalização, territorialização e enraizamento cultural e de outro mediação pela qual o homem em sociedade intervém nos dados natural-locais para transformar a natureza e ele mesmo em sociedade. Historicamente, é a derivação como determinado e determinante da relação das comunidades humanas com o seu meio geográfico. A relação de copertencimento que por isso meso intervém ao tempo que mantém sociedade e natureza num estado dinâmico de equilíbrio. Daí Sorre sempre vêla como elo-chave de um complero. A enxada e o arado formam, por exemplo, um todo com o cultivo do arroz e a criação das aves no complexo da rizicultura do Sudeste asiático. E o trator com as culturas especializadas no começo da agricultura industrial moderna. Mas a técnica encarna também, desde o seu surgimento, um princípio de racionalidade (Sorre, 1967; Santos, 1994 e 1996). De modo que já no começo da história dessacraliza a natureza e radicaliza o processo que (des)ambientaliza, (des)territorializa e (des)enraíza as comunidades humanas em sua relação ao seu entorno geográfico.

\section{A territorialização}

A integração técnica se desdobra na territorialização, o terreno da demarcação simbólica e valorativa dos domínios de espaço. E que ao tempo que geografiza, separa e cultural e politicamente distingue as comunidades entre si. São muitas suas formas conhecidas.

Nas sociedades comunitárias mais antigas, em geral ainda nômades ou entregues ao semi-nomadismo, o recorte territorial tem uma forma tão vaga quanto o é seu movimento de enraizamento ambiental. O processo da ambientalização está ainda se realizando e a noção de território é algo ainda esmaecido. Já nas sociedades de classes antigas e modernas, onde surge o Estado e junto a ele a cidade, o território ganha a precisão de um recorte de domínio claro de espaço. A cidade inscreve, fixa e 
circunscreve o domínio terrirorial do Estado, formaliza o presença político-cultural do Estado e lhe injetando o conteúdo simbólico do poder de classe que ele exprime e incorpora.

\section{A politização}

Isso significa dizer que espaço é política. A dimensão que exprime e transce a relação do território. O território é sempre uma dimensão política do espaço (ou ao espaço tomado como dimensão política). Mas a condição política é em si uma condição espacial da própria geograficidade. $\mathrm{O}$ fato de a geograficidade significar uma relação em que seus habitantes coabitam e se diferenciam por seus marcos de espaço. Marcos que incluem a tensão, fruto de o espaço nascer, desde seu cunho de unomultidiversidade, do signo da contradição. Contradição entre localização e distribuição, que se estabelece no momento mesmo da seletividade. E daí se desdobra numa oposição, não necessariamente antagônica, de alteridade-centralidade, unidadediversidade, hegemonia-heterogenia e identidade-diferença, a depender da natureza social da sociedade que se viva (Moreira, 2007b).

A contradição alteridade-centralidade é a base. Qualificada como uma ou como outra, a depender do marco posicional da localização. Se referida a um ponto único do território, a localização significa o olhar da centralidade. Se referida à multiplicidade de pontos, e assim transmutada numa distribuição, a localização significa o olhar da alteridade. A referência na centralidade da localização determina o primado do uno. A referência na alteridade da distribuição determina o primado do múltiplo. A localização como dado único fala de um lugar central em relação ao espaço circundante. A localização como dado múltiplo da distribuição fala do múltiplo recíproco da outridade. O espaço do eu egocêntico, da exclusividade do único. O espaço dos tantos outros, da reciprocidade do múltiplo. Em suma. Centralidade e alteridade surgindo como referências de arranjos políticos opostos, na construção geográfica das sociedades. Opostos perceptivos, conceptivos e valorativos das formas socioespaciais de cada qual delas.

A contradição entre a unidade e a diversidade é o desdobramento da base alteridade versus centralidade. O princípio da localização rege o uno. O princípio da distribuição rege o múltiplo. Assim, o princípio da localização valoriza a unidade, enquanto o princípio da distribuição valoriza a diversidade. Uno e múltiplo tendem a se 
$\overline{\text { anular reciprocamente, pois, na interatividade. A unidade age no sentido de internalizar }}$ e assimilar a diversidade dentro do uno. A diversidade, no sentido de como tal realizarse plenamente dentro e como múltiplo. Então, o olhar de um contradita o olhar do outro.

A contradição hegemonia-heterogenia vem como o desdobramento seguinte, a homogenia desdobrando a unidade e a heterogenia a diversidade, quando a contradição unidade-diversidade se agrava e não se resolve. A contradição gira seu jogo agora em torno do aumento do conflito: estruturado no símbolo da unidade, o espaço da localização vira homogenia; estruturado no símbolo da diversidade, o espaço da distribuição vira heterogenia. Temos, assim, heterogenia e/ou homogenia, conforme o aspecto do princípio alteridade-centralizadade que prevaleça na base da organização do espaço.

A contradição identidade-diferença, por fim, fecha o ciclo, desdobrando os aspectos da contradição. homogenia-heterogenia. A identidade surge da centralidade que emana do princípio unicista da localização. A diferença surge da alteridade que emana do princípio diversificacionista da distribuição. A centralidade da localização produz a identidade. A alteridade da distribuição, a diferença. O princípio da localização trabalha a favor da identidade, enquanto o princípio da distribuição trabalha a favor da diferença, em suma. Também aqui a contradição seguindo uma clara evidência: a sutileza da homogenia dá lugar à sutileza da identidade, suprimindo a diferença; a transparência da heterogenia dá lugar à riqueza da diferença, mediatizando a identidade.

\section{A regulação}

A contradição suscita a regulação, relação que vem junto e no espírito do controle sistêmico. Refere-se ao conjunto de regras, normas e princípios de natureza regente do espaço. O veículo é o formato do arranjo - econômico, jurídico, político, cultural, representacional e ideológico - do espaço (Moreira, 2007a), montado a partir do processo da seletividade e por fim ordenado como modo de organização espacial da sociedade. Lacoste designa-o espacialidade diferencial (Lacoste, 1988). Lefebvre condição de reprodutibilidade (Lefebvre, 1973). Quaini regulação, explicitamente (Quaini, 1979). 


\section{A mobilidade}

A mobilidade é o resultado de toda essa dinâmica. E ao lado das tensões, o alvo da regulação. Mobilidade dos homens, das plantas e dos animais, mas também de produtos e capitais. Mobilidade que troca os sinais da distribuição dos cheios e vazios da seletividade inicial, numa permanente rearrumação das formas dos arranjos. Mobilidade que mina a territorialização, refaz a ambientalização e recria o enraizamento cultural, via o ordenamento que reafirme ou redistribua os lugares da tensão.

O veículo técnico da mobilidade é por excelência a expansão dos meios de transferência (transporte, comunicação e transmissão de energia). No passado, "o viajante que atravessasse a França, encontrava alternativamente uma vila de simples descanso ou uma cidade de completo repouso: a primeira bastava ao pedestre, a segunda convinha ao cavaleiro", diz Reclus, de vez que "o ritmo das populações, a cadência natural calcada na marcha dos homens, dos cavalos e das carruagens" marcava o movimento do espaço (Reclus, 1905). Com o advento da indústria, a rede dos meios de transferência se espalha e se acelera. A evolução dos transportes, dos meios de comunicação e do sistema de transmissão de energia diminui a distância e articula a relação entre os lugares em escala planetária. Os constrangimentos da gravidade são superados, no dizer de Sorre, num "triunfo definitivo do homem sobre o espaço" (Sorre, 1967).

\section{A urbanização}

A urbanização é o efeito expansivo da mobilidade. Fruto da reorganização radical que advém do rearranjo do espaço herdado pelo planeta. Durante séculos a paisagem rural foi o quadro de arrumação geográfica das sociedades. A evolução técnica e dos intercâmbios quebra aqui e ali a tradição, mas não libera a mobilidade migratória para a cidade. Com a capitalização do campo e a aceleração dos meios modernos de circulação que ela promove, os grupos humanos saem em ondas dos territórios aos quais estiveram presos por longo tempo, migram do campo, trocam de lugares com a cidade e mesmo mudam de continente. A população rural abandona o espaço rural em crescendo, alterando os cheios e vazios das velhas arrumações. A urbanização vai assim avançando, primeiro localmente, depois em escala planetária, aumentando o intercâmbio de produtos, mudando hábitos de consumo, dissolvendo 
$\overline{\text { antigas culturas. O mundo rural então recua em todos os cantos, em proveito do mundo }}$ urbano. O próprio campo com o passar do tempo se torna urbano. E segundo três fases, a caminho de tornar o mundo inteiro uma civilização urbana: primeiro a cidade e o campo se separam; depois, a cidade se torna o destino da população do campo; por fim, a cidade retransfere população, invade e urbaniza o campo. Ao tempo que em todo canto o espaço se rurbaniza, a população urbana se transcontinentaliza, transcontinentalizando o fenômeno urbano.

\section{A compressão}

A compressão do espaço é uma consequência da urbanização e da mobilidade. A mobilidade que redistribui e urbaniza, comprime e diminui no sentido sócio-físico as distâncias no planeta. A velocidade dos transportes e comunicações instantaneíza as trocas, as transações financeiras e torna tudo simultâneo. Reclus já a observa no século XIX. Vidal na evolução que arruma os transportes em rede. Sorre no entrelaçamento dos ecúmenos. Santos na empiricização que transforma o tempo em espaço. Harvey no encolhimento do planeta.

\section{A fluidificação}

A fluidificação é o campo geral dos desdobramentos. Da mobilidade e da compressão vem a eliminação das fronteiras, a integração mundial em rede. A liquefação dos desenhos. O movimento que torna liso e fluido.

De início, localizar e distribuir elementos significa criar espaços fechados. Tudo está preso localmente ao nível estrito da comunicação e transporte. O poder de locomoção é mínimo. O raio de alcance diminuto. As informações de um lugar demoram a chegar a um outro. A troca territorial é lenta. A fluidez inexiste. É isso o espaço-tempo das sociedades no começo. Tudo, no entanto, muda nos anos 1950 (Moreira, 2006). Os fluxos ganham movimento. Primeiro as trocas, depois os homens, por fim os dados, tudo se desloca de um ponto a outro. Num tempo de extensão sóciofísica que fica cada vez menor. O espaço lento se dissolve. A seletividade fludifica. A interação entre os lugares aumenta. É o tempo-espaço das sociedades modernas

O ente integrador é mais uma vez a cidade. O fixo que faz o fluxo (Santos, 1996; Smith, 1988). Se reproduz nas manchas das culturas e das pastagens. Urbaniza o rural 
no fluxo da circulação. $O$ fluxo do desenho animado que redesenha o fixo. Retransfigura os arranjos. Cujo auge é ciberespaço. O espaço que, ao fim, se desmaterializa. Se desregionaliza. Dissolve as compartimentações.. E valoriza a relação em rede (Moreira, 2000).

\section{A sociodensificação}

A sociodensificação é o grande produto. Fluido, liso e híbrido o espaço se espessa. Aumenta o volume na medida que a densificação cria o tecido espacial onde natural e social, urbano e rural, local e global trocam-se como formas do mesmo.

Resta apenas a fronteira tênue da quantidade e da qualidade. A quantidade que se identifica como qualidade. A qualidade que se identifica como quantidade. Porque densidade passa a ser a intensidade da grossura do tecido espesso. A espessura das relações, fonte do número, que faz da escala a densidade da grade relacional (quanto mais densas as relações, mais absoluta e relativamente denso-tenso é o espaço).

\section{A reestruturação}

O espaço densificado assim se satura. E é necessário reestruturá-lo. Reverter o mapa da seletividade. Redesenhá-la. Reinscrever e reconfigurar suas densidades-tensões locacional-distributivas. Num retorno do ciclo. O recomeço ao ponto-início da montagem.

No longo do curso de agregação de prática espacial em prática espacial, três momentos se distinguem no curso constitutivo da construção geografica da sociedade: a fase da montagem, praticamente restrita à prática da seletividade; a fase do desenvolvimento, de agregração, por desdobramento e edificação estrutural, da espacialidade começada no ponto-início na seletividade; e a fase da reestruturação, reconfigurativa. Por agregação de arranjos de prática a prática a armadura ganha peso e escala. Até a denso-tensificidade esgotar a capacidade do arranjo assimilar relações novas. $\mathrm{O}$ ciclo se fecha. $\mathrm{E}$ um novo ciclo construtivo se abre, com a reestruturação que recria e refaz o poder integrativo do arranjo. É o tempo de uma relação sociedadeespaço nova. Com o mesmo sentido de valor. Ou o valor novo que tudo ressignifica.

A estrutura espacial da sociedade moderna conhece três épocas históricas desse reciclo, cada qual correspondente o um período de era técnica: a fabril da primeira 
$\overline{\text { revolução industrial, a fabril da segunda revolução industrial e a ciberfabril da terceira }}$ revolução industrial (Moreira, 1998b, 1999, 2000 e 2007a). A primeira é a época do espaço estruturado na centralidade da fábrica. É o período seletivo-redistributivo das plantas e animais que as grandes navegações intercambiam pelos continentes. Período do arranjo da sociedade em regiões homogêneas e relação internacional centralizada nas grandes praças de mercado da Europa, o grande espelho dos espaços coloniais arrumados em sua identidade e proveito. A segunda é a época da centralidade fabril mundial. Período da mobilidade técnica da ferrovia, depois rodovia e navegação aérea, no campo dos transportes, do telégrafo, depois telefonia, nas comunicações. E da hierarquia das regiões polarizadas centrada nas redes de comando das cidades industriais. E a terceira é a época atual, de desterritorialização e dissolução do poder espacial da indústria, da polaridade do serviço e da finança rentista, da informação como matéria-prima e da sociedade em rede. Dos grandes empórios urbanos de consumo de massa.

Em cada uma dessas fases o retorno à seletividade é o recomeço. O mapa dos cheios e vazios dos arranjos que se recria. O todo se redinamiza. Um novo bloco histórico alicerçado num novo plano estrutural de seletivida, que tudo recentraliza, cria um novo arco de homogenia e hegemonia. Formas regulatórias de tensão e reprodutibilidade novas orientam formas novas de coabitação de espaço.

\section{AS PRÁticas E SABERES ESPACIAIS E A FUNÇÃo MEDIADORA DA PERCEPÇÃO E DA IDEOLOGIA}

Todas essas práticas e os saberes espaciais são práxis instruídas na percepção e na ideologia. A percepção que alimenta o movimento constitutivo da noção. E a ideologia subjacente à ideação do conceito. Dois elementos antagônicos que conflitam no trânsito do movimento que converte o par prática-saber do senso-comum no par prática-saber do saber científico.

A percepção, mestra seja da noção e seja do conceito, é aí uma categoria de mediação. A categoria da passagem da prática e do saber, seja da noção, seja do conceito, em seu vai-vém de conversão recíproca. Por isso instância reguladora dos acertos e reacertos dos ajustes e reajustes que orientam sua reciprocidade. E o sinal, antes que a noção e o conceito, do momento preciso da mudança. 
Ponto de referência do começo e recomeço, a seletividade é uma prática de natureza perceptiva por excelência. A bússula que dirige o modo de arranjo espacial efetivo que o binômio localização-distribuição aqui e ali instala em sua pertinência de sincronia e diacronia com os resultados pretendidos da geograficidade - o ser-estar espacial do homem - almejada pela intervenção humana. Colada ao dia-dia da práticas espaciais como categorias do empírico geográfico, é a percepção que sinaliza à sociedade para o papel necessário de uma teoria de espaço em seu processo constitutivo de construção geográfica.

A ideologia põe-se nesse mesmo tronco, mas como categoria da representação. Categoria que intermedia a relação transfigurativa recíproca do saber e da prática espacial, mas a partir da interface da noção e do conceito, do senso comum puro e simples e da teoria abstrata da ciência.

A percepção localiza-se na essência da prática espacial, o plano da abstração mental que extrai a noção que o transforma no saber espacial. A ideologia localiza-se na interface, o plano da transversalidade do saber do senso comum a caminho do logos da abstração científica. Um exemplo pode ajudar a compreendê-los. Todos nós moramos em um lugar. E todos temos familiares e amigos que moram em lugares. Estes lugares são ligados por ruas, avenidas, estradas. Pessoas, objetos e idéias fluem entre eles, entrecruzam-se através suas artérias. Ajudam-se ou ignoram-se. Cedo a percepção nos faz ver nesses traços a escala geográfica que os dimensiona. Os diferentes meios de vida que daí são extraídos. Os objetos úteis em que são transformados. E que o intercâmbio disponibiliza entre os homens. Do e entre os lugares. E cedo depreendemos também que é de tal combinação que se tece o ser-estar espacial que determina nosso modo real de existência. A pluralidade dos núcleos, que reconhecemos na residência, na fábrica ou na escola, cujo conjunto compõe o nosso mundo. Núcleos espaciais que justapõem, embutem e inscrevem nosso modo de ver esse todo. Aqui pelos olhos microespaciais da família, ali da fábrica, acolá da cidade, mais além do país, que chamamos nosso mundo. Assim nascendo a representação. A dimensão da escala habitada pela ideologia. Mas igualmente da percepção que a informa de empiria. Lugar de passagem da singularidade à universalidade, a representação é, assim, o meio caminho entre a falsa e a verdadeira teorização, a ideológica e a científica, a depender dos olhos crítico da percepção que as contempla e do olhar classista que especifica e diz na imagem e na fala o que vê. De que o movimento aparente do sol é o melhor exemplo. Típico exemplo de fronteira da percepção e da ideologia transfiguradas em representação. A representação que pelos 
olhos ideológicos da igreja medieval identifica a onipresença, onipotência e onisciência de um ser supremo. E pelos olhos da ciência diz apenas do modo como, por ordenação de regras matemáticas, os entes da natureza movem-se de modo ordenado pelo amplo espaço estelar.

O saber que chamamos Geografia é o campo talvez mais comum desse plano duplo de interseção da noção e do conceito, do senso comum e da ciência, da percepção e da ideologia. Dado seu cunho de um combinado do empírico e do abstrato, do singular e do universal, da noção e do conceito, entes de essência das práticas e saberes espaciais, percepção e ideologia desde as origens são o elo do poder de fogo e sua indiscutível popularidade

Dessa base de fundo ontológico é que sai o fundamento de seu traço epistemológico. A condição de ciência alicerçada na singularidade da percepção brotada em linha direta das práticas e saberes do espaço e na peculiaridade da ideologia de hábito situada na fronteira do conceito e do logos do discurso científico, de onde extrai o atributo de forma de olhar e ler o mundo a partir do que se vê, é a fonte de onde emana o modo de saber que se de um lado pode servir os homens em sua busca de uma humanidade resolvida em "seus problemas de vida e de felicidade", como dizia o velho Estrabão em sua fundação como ciência nos longos idos do século I, de outro pode servir também para delas aliená-los. Propriedade que, se no seu plano mais amplo encontramos em qualquer forma de saber na moderna sociedade de classes, no plano doméstico do sistema de ciências se revela uma especificidade quase exclusiva da Geografia. O saber, já advertia Lacoste, que falando do que perceptivamente parece o óbvio, mostra-se por isso mesmo a forma de ideologia mais perigosa.

Já a geografia acadêmica se dizia um saber terra-a-terra, concebendo que aquilo com que o saber geográfico lida é a realidade em si mesma por demais evidente, bastando apenas o olhar da percepção para conhecê-lo, no fundo escondendo que a percepção, deixada justamente por si mesma, pode servir a deus e ao diabo. Ora, querendo, a percepção diz o que queremos que ela diga. Em nada se distinguindo da pura ideologia. Campo de batalha onde se trava a disputa da ideologia e da ciência, a percepção pode, entretanto, confirmar ou desdizer o que se afirma por realidade. Não bastasse o exemplo do movimento aparente do sol, vale o dito do povo que "as aparências enganam", inspirado no que as práticas espaciais e sua revelação nos saberes espaciais, justamente, a todo instante ensina.

O que dá à Geografia a propriedade da proximidade da mediatez, tanto quanto 
da imediatez do espaço vivido. Onde a percepção se põe e se opõe de par em par à ideologia. E por isso a propriedade igualmente de distinguir o que é de uma e o que é de outra. Onde tanto a ideologia quanto a ciência se valem do real-aparente, o real que a percepção extrai das práticas espaciais para montar a verdade do discurso dos saberes. E a ideologia a matéria prima de sua condição de leitura inversa do verdadeiro. A percepção como chave da consciência. E a ideologia como matéria prima da falsa consciência. A fronteira tênue da fronteira onde a explicitação do real visto por um lado, o ideológico, se confunde e visto por outro, o perceptivo, se elucida. Mesmo que coabitantes do mesmo. O universo das práticas e saberes do espaço. Foi com esse intuito que Marx observou, em página conhecida de $O$ Capital, que "a ciência seria desnecessária se toda essência coincidisse com a sua aparência" (Marx, 1985). Como que falando do vivido como o mundo duplo do aparente e do essente, do percebido e do concebido, do concreto-empírico e do concreto-pensado, do real aparente e do real-real, categorias da prática e do saber espacial, cerne direto dos discursos de geografia e da Geografia.

\section{BIBLIOGRAFIA}

BAUDRILLARD. Jean. A Troca Simbólica e a Morte. Lisboa : Edições 70, 2 volumes, 1996 . Simulacros e Simulação. Lisboa : Relógio D’Água, 1991

BRUNHES, Jean. Geografia Humana. Rio de Janeiro : Editora Fundo de Cultura, 1962.

HARVEY, David. Condição Pós-Moderna. Uma pesquisa sobre as origens da mudança cultural. São Paulo: Edições Loyla. 1992.

LACOSTE, Yves. A Geografia - Isso Serve, em Primeiro Lugar, Para fazer a Guerra. São Paulo: Editora Papirus, 1988.

LEFEBVRE, H. A Re-Produção das Relações de Produção. Lisboa : Publicações Escorpião, 1973.

MARX, Karl. $O$ Capital. Crítica da economia política. Rio de Janeiro: Editora Civilização Brasileira, 1985.

MELO, Hygina Bruzzi. A Cultura do Simulacro. Filosofia e modernidade em J. Baudrillard. São Paulo: Edições Loyola, 1988

MOREIRA, Ruy. A geografia serve para desvendar máscaras sociais. In. Pensar e ser em geografia. São Paulo: Editora Contexto, 2007a. 
. A sociedade e suas formas de espaço no tempo. In.

Pensar e ser em geografia. São Paulo: Editora Contexto, 2007b.

O mal-estar espacial no fim do século XX. In.

Pensare

ser em geografia. São Paulo: Editora Contexto, 2007c.

O espaço e o contra-espaço: as dimensões territoriais da sociedade e do Estado, do privado e do público na ordem espacial burguesa. In: Território, Territórios: ensaios de ordenamento territorial. Rio de Janeiro: Editora Lamparina, $2007 b$.

Da região à rede e ao lugar: a nova realidade e o novo olhar geográfico

sobre o mundo. In. . Para onde vai o pensamento geográfico? São Paulo:

Editora Contexto, 2006.

Os Períodos Técnicos e os Paradigmas do Espaço do Trabalho. In:

Ciência Geográfica. Bauru : AGB-Bauru, ano VI, no. 16, 2000.

O Paradigma e a Ordem. Genealogia e metamorfoses do espaço capitalista. In: Ciência Geográfica. Bauru : AGB-Bauru, ano V, no. 13, 1999.

Desregulação e Remonte no Espaço Geográfico Globalizado. In Ciência Geográfica. Bauru: AGB-Bauru, ano IV, no. 10, 1998b.

QUAINI, Massimo. Marxismo e geografia. São Paulo: Editora Paz e Terra, 1979.

RECLUS, Elisée. El Hombre y La Tierra. 6 volumes. Barcelona : Casa Editorial Maucci, 1905.

SANTOS, Milton. Técnica, Espaço, Tempo. Globalização e meio técnico-científico informacional. SãoPaulo : Editora Hucitec, 1994.

A Natureza do Espaço. São Paulo : Editora Hucitec, 1996.

SMITH, Neil. Desenvolvimento desigual. Natureza, capital e a produção do espaço. São Paulo: Bertrand Brasil, 1988.

SORRE, Max. El Hombre en la Tierra. Barcelona : Editorial Labor S/A, 1967.

VIDAL LA BLACHE, Paul. Princípios de Geografia Humana. Lisboa : Edições Cosmos, 1954. 